Caras (os) colegas,

Este número especial da Revista Portuguesa de Enfermagem de Saúde Mental (número 11) pretende compilar artigos, relativos aos trabalhos apresentados no IV Congresso Internacional da ASPESM, dedicado aos Padrões de Qualidade em Saúde Mental, realizado nos dias 10 e 11 de Outubro de 2013 em Coimbra. Os restantes artigos são divulgados em E-book - Padrões de Qualidade em Saúde Mental, como ISBN no 978-989-96144-5-1, disponível no site da ASPESM - www.aspesm.org. Esta é uma metodologia que pretendemos manter nos próximos eventos com o intuito de disseminarmos o conhecimento em Enfermagem de Saúde Mental, por um maior número de profissionais de saúde.

Este número, ficou com um total de 20 artigos o que implicou um esforço acrescido dos elementos da comissão editorial e da comissão científica, aos quais queremos expressar o nosso agradecimento, pois só assim é possível manter os critérios de qualidade e disseminar o maior número de trabalhos possível.

Os temas abordados são muito variados e integram o ciclo vital: infância, adolescência, jovens adultos, adultos e pessoas mais velhas, bem como, os diferentes contextos de intervenção em saúde mental. Incluímos temáticas sobre a promoção da saúde mental, a prevenção da doença mental; instrumentos de avaliação que aportam um maior rigor aos processos diagnósticos; estudos sobre a efetividade das intervenções, e, estudos sobre resultados em termos de ganhos em saúde para as pessoas, famílias e comunidades.

\section{Padrões de Qualidade em Saúde Mental}

Entende-se por padrões de qualidade na prática clinica a sistematização de uma ação em resposta a uma necessidade em cuidados de saúde de uma pessoa, família ou comunidade, num determinado contexto e num determinado momento, que traduza a intervenção mais efetiva, de acordo como os dados disponíveis no momento da sua prescrição e execução.
O padrão significa uma estrutura mínima do que é expectável, desejável, e qualidade significa boa prática, ou seja, a melhor prática de acordo com a evidência disponível.

Por isso, os Padrões de Qualidade são indissociáveis da investigação, uma vez que esta é a via por excelência, para definirmos o padrão (comunalidade entre os casos/situações similares) e qualidade como a estratégia que está associada a melhores resultados, ou seja, maiores ganhos em saúde.

Os Padrões de Qualidade são um instrumento fundamental, quer para os profissionais de saúde, quer para as pessoas: Para os profissionais de saúde porque servem de guias orientadores da prática clinica; para as pessoas porque constituem um suporte de segurança, uma garantia de qualidade da resposta.

Em Saúde Mental os padrões de qualidade ainda merecem um maior destaque por várias razões: i) por vezes, a doença mental limita a capacidade de decisão da pessoa e por isso uma menor participação na tomada de decisão; ii) a doença mental pode interferir na capacidade de compreensão e de ajuizar sobre o seu problema devido ao compromisso da cognição; iii) a doença mental constitui um fator vulnerabilidade individual porque implica um compromisso da funcionalidade; iv) a Doença mental está associada a vulnerabilidade social devido ao estigma ainda presente na maioria das comunidades. Daí a importância de se definirem as práticas de qualidade de modo a que a intervenção esteja associada a um maior potencial de eficácia possível.

Os padrões de qualidade referem-se aos processos (procedimentos), aos conteúdos da prática clinica e aos requisitos para a sua implementação com segurança para ambos os intervenientes em interação. Para a definição dos processos e dos conteúdos importa definir o que se entende pela ação dos enfermeiros nos diferentes contextos. De forma muito sintética, poderemos dizer que os enfermeiros ajudam as pessoas, nos processos de saúde a viver melhor (com mais saúde e durante um maior período de tempo) e ajudam as pessoas nos processos de doença a minimizar as consequências negativas 
da mesma promovendo uma melhor recuperação (mais rápida e mais efetiva). A sua ação concretizase ao nível da promoção da saúde, da prevenção da doença, no tratamento, reabilitação e reinserção da pessoa. Em saúde mental uma ação significativa também está relacionada com a capacitação da pessoa e dos seus familiares cuidadores para lidarem com as adversidades (empoderamento - capacidade de resolução de problemas - saúde mental positiva). Em qualquer dos registos importa referir que a ação profissional dos enfermeiros se pode agrupar em três dimensões:

i) Processo diagnóstico com o intuito de caracterizar uma determinada necessidade em cuidados de enfermagem. Nesta dimensão é fundamental definir as áreas de intervenção autónomas e partilhadas entre os enfermeiros de cuidados gerais/Enfermeiros especialistas e entre os enfermeiros/outros profissionais. Reitera-se que a noção de diagnóstico aqui descrito não se circunscreve à associação a um processo de doença, mas sim, à avaliação que, traduz a necessidade de intervenção do enfermeiro, quer seja ao nível da promoção, da prevenção e do tratamento. Quando os recursos são limitados, um diagnóstico rigoroso é fundamental para a sua otimização. Por isso, para que este processo cumpra os pressupostos de qualidade é necessário definir, face a cada situação/contexto, quais os dados mínimos que nos permitem enunciar determinado diagnóstico; quais os instrumentos de avaliação/escalas que devem ser utilizados, quais os critérios para a utilização de determinados instrumentos, (...). Cada instituição deveria disponibilizar aos seus profissionais estas informações, de modo a orientar os enfermeiros sobre o que deve ser feito, em situações ideais (padrão de qualidade) e depois compete ao enfermeiro avaliar a situação real e adaptar o padrão a cada contexto. Por exemplo, neste registo é habitual diferentes instituições utilizarem diferentes instrumentos para avaliar situações similares sem qualquer justificação para tal. Um padrão não significa fazer tudo da mesma forma por todos, mas implica diversos consensos sustentados na evidência científica. Por isso, é importante consensualizar linguagens, taxonomias, processos, e produzir investigação que nos permita dizer que o processo " $\mathrm{A}$ " tem vantagens face ao "B" e ao "C". ii) Uma outra dimensão refere-se às intervenções de Enfermagem. Estas podem ser subdivididas em duas categorias: a) as Intervenções Interdependentes - Iniciadas por outros técnicos, nas quais os enfermeiros se responsabilizam pela sua implementação; b) as intervenções autónomas Iniciadas pela prescrição do enfermeiro, nas quais os enfermeiros se responsabilizam pela sua prescrição, implementação e avaliação. No domínio das intervenções os padrões de qualidade devem: a) Garantir que há relação entre as intervenções e os diagnósticos, ou seja, que determinados diagnósticos são indicações terapêuticas de determinadas intervenções. b) Identificar quais as intervenções que revelam maior efetividade terapêutica; c) identificar as intervenções major e minor para cada diagnóstico; d) Descrever quais as atividades que concretizam cada intervenção, ou seja, qual o conteúdo que cada intervenção deve incorporar, de modo a promover a congruência entre utilizadores de léxico e de conteúdo. Ex: quais as atividades mínimas a incluir na intervenção "suporte emocional"; e) Identificar os processos que devem nortear as intervenções, quais os procedimentos, qual a melhor forma de implementar uma determinada intervenção, pois em saúde mental, a forma pode ser determinante para a efetividade da intervenção.

iii) Uma outra dimensão está relacionada com os contextos e os requisitos que os mesmos devem "respeitar" para facilitarem a implementação de práticas de qualidade e garantirem a melhor recuperação das pessoas. Assim, teríamos pela via dos padrões de qualidade que determinada intervenção implica a existência de determinados recursos. Por exemplo, para a implementação da Intervenção "relação de ajuda formal; reestruturação cognitiva, relaxamento" são necessários espaços físicos com determinadas características que garantam a privacidade das intervenções; enfermeiros Especialistas (dotações seguras) que possam garantir a prescrição, a execução e continuidade das intervenções, (...). Nesta dimensão inclui-se também as características das estruturas que devem ter determinados serviços, em função da natureza dos seus utentes e dos objetivos dos mesmos. Uma unidade de demência deve ter características diferentes de uma unidade de urgência ou de uma unidade de cuidados continuados. 
Os padrões de qualidade devem integrar os requisitos das estruturas assistências, a matriz dos processos diagnósticos e a estrutura base das intervenções, tendo por base os indicadores epidemiológicos, os indicadores de estrutura, indicadores de processo e indicadores de resultado.

Nesse sentido, para os focos de atenção mais frequentes em cada contexto devia existir um $\mathrm{Pa}-$ drão de qualidade que orientasse os profissionais de saúde para: quais os dados a recolher para cada foco; quais os dados major e a necessidade de utilização de instrumento de medida validado; qual o melhor enunciado diagnóstico face a um determinado conjunto de dados; quais as intervenções que são aconselhadas por níveis de efetividades e quais os resultados esperados em função da implementação de determinadas intervenções.

Conclui-se que os padrões de Qualidade são importantes para:

- Estimular a reflexão sobre as práticas;

- Dar consistência ao conhecimento em enfermagem;

- Trazer imparcialidade ao cuidado dos diferentes pacientes;

- Avaliar a eficiência associada às intervenções de enfermagem;
- Avaliar a qualidade das práticas de enfermagem;

- Garantir práticas que cumpram requisitos científicos e estejam em consonância com a evidência empírica;

- Promover a integração dos resultados de Investigação na prática clinica e a sua reformulação;

- Aumentar a eficiência nos resultados;

- (...).

Os padrões de Qualidade devem informar sobre "O Que Fazer", "Como Fazer" e qual a "Utilidade Social" (resultado efetivo) esperada do fazer.

A sua construção é um trabalho contínuo, de todos os agentes envolvidos quer na formação quer na prática clinica, pelo que devem ser congregadas sinergias das várias entidades (Instituições de ensino e de investigação; Instituições de assistência; Ordens profissionais, Sociedades científicas,...) na sua edificação.

Porto, 30 de Março de 2014

O Diretor da Revista d' ASPESM

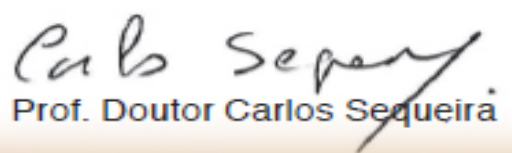

